\title{
ENGLISH TEACHER PROFESSIONAL DEVELOPMENT IN INDONESIA: THE CHALLENGES AND OPPORTUNITIES
}

\author{
Anchieta Ave Avillanova \\ The English Education Master Program, Sanata Dharma University, Indonesia \\ E-mail: anchieta.ave@gmail.com \\ Paulus Kuswandono \\ The English Education Master Program, Sanata Dharma University, Indonesia \\ E-mail: kus@usd.ac.id
}

\begin{abstract}
APA Citation: Avillanova, A. A., \& Kuswandono, P. (2019). English teacher professional development in Indonesia: The challenges and opportunities. English Review: Journal of English Education, 8(1), 41-50. doi: 10.25134/erjee.v8i1.1972.
\end{abstract}

Received: 02-10-2019

Accepted: 10-11-2019

Published: 01-12-2019

\begin{abstract}
This study investigates the challenges and opportunities of junior high school English teacher professional development in Indonesia. The objectives of the study are to examine the English teachers' challenges and needs to develop their TPD. This qualitative study employed questionnaire and in-depth interview as the main instruments for data collection. The findings revealed that the challenges of TPD related to, firstly, program timing as the program was carried out during working hours; and, secondly, lack of information about workshop schedule from the government (Education Office) because, geographically, some schools are located in remote areas. The study also explored the teachers' needs for TPD concerning student assessment, classroom management, knowledge and understanding of English, content of performance standards, giving instruction, ICT skills for teaching, teaching students with special learning needs, and school management and administration. Suggestion for further study concerns with the bottom-up approach of carrying TPD based on the teachers' real needs as opposed to given programs.
\end{abstract}

Keywords: junior high school; English teachers; teacher professional development; challenges; needs.

\section{INTRODUCTION}

Studies on teacher professional development (TPD) have been an essential part of educational discipline as it is closely associated to improve the quality of education (Bank \& Mayes, 2012; Darling-Hammond, Hyler, \& Gardner, 2017; Tanang \& Abu, 2014). Besides, TPD is often linked to learning opportunities for teachers who have different background, level of confidence, and motivation to develop themselves (Whithworth \& Chiu, 2015). However, the practice of teacher professional development program can pose some extensive challenges. In their study, Whithworth and Chiu (2015) argue that teachers' background experiences may substantially affect the decision as to whether or not they wish to attend professional development programs. If teachers realize that they do not have enough experiences on teaching, they are aware of the need to attend professional development programs to learn new educational experiences to develop themselves. In contrast, for those who assume that they have already got adequate professional experiences, they may not aspire to participate in the TPD program anymore.
Teacher professionalism means "an approach to educational reform - as improving teacher quality became viewed as the key to student achievement..." (OECD, 2016, p. 8). Thus, improving teachers' quality as one of the fundamental factors in education directly affects the students' learning attainment. In fact, every country all over the world has its own way to develop teacher professionalism. In Indonesia, starting from 2006, the Ministry of Education establishes a program named teacher certification in order to develop teacher professionalism and to produce more qualified teachers. Nonetheless, teacher certification is indeed only one of the means to develop teachers' professionalism in Indonesia.

The goals of the teacher certification program are, among others, to ensure that the teachers perform their job properly, to improve the quality of education, to improve teachers' professionalism, and to show that the teachers already have obtained sufficient competency to perform as teachers. Article 1 of Indonesia's Teacher and Lecturer Law Number 14 Year 2005 states that a teacher is a professional educator who should master four competencies, namely: 
pedagogy, professionalism, social, and personality. The most interesting benefit for the teachers who have got the certification is that they get financial incentives to support their professional and daily needs. This becomes one of the motivations for teachers because, in fact, the teachers' salary in school tends to be small (Kuswandono, 2014, p. 2). It is also in line with Fahmi, Maulana, and Yusuf (2011) who argue that the certification can improve teachers' welfare. Since the teacher certification is found to be beneficial for the teachers, many teachers who meet the requirements in following teacher certification register themselves in the program. Nevertheless, the teacher certification can be highly laborious for many teachers as this requires reliable teachers' professional portfolio and sufficient cognition on most recent pedagogy.

There have been some previous studies on teacher certification in Indonesia which investigate the program outcome. Wahyudi, Supranoto, and Suji (2012) argue that although not yet satisfactory, the teacher certification gives positive results. Another study by Kuswandono (2014) reveals that there are some problems in the teacher certification programs, namely, "the problematic nature of standardization as a result of 'deficit model' approach of PD, an elusive link between performance and reward, an external motivation, 'one shot program', and limited resources and facilities" (p. 5). Indeed, it is difficult to standardize all of teachers in Indonesia. However, this may become a way to improve and make the education in Indonesia equal.

Within the contexts of teacher certification and professional development, continuous professional development done after the certification is also needed to improve the quality of the teachers. It can also promote improvements in teaching (Kennedy, 2016, p. 1). However, the continuous professional development is found limited as Kuswandono (2014) states in his study that "after the teachers receive their educator certificate, there is no clear, continuous support for professional development (PD) to maintain any learning they did during the certification process or to improve the quality of their teaching" (p. 8). Therefore, this current study intends to explore better understanding about professional development in terms of experiences and challenges experienced by English teachers in junior high schools in
Indonesia, especially in Cilacap Regency, Central Java, Indonesia.

To make the research setting clearer, Cilacap Regency is a small city which is located in the southern part of Central Java, Indonesia. This study is urgent for Indonesia and other countries where the top-down education becomes the fundamental element in education. Besides, there have not been many studies focusing on the TPD in a smaller area such as Cilacap Regency, Central Java, Indonesia.

In this study, there are two main points used as the underlying theories. The first one concerns with the definition of TPD; while the second relates to the factors that influence TPD. Those theories are elaborated as follows.

As previously described, teachers need professional development to develop themselves in terms of teaching and learning. It is equally important to have professional development because, based on the study by Taylor, Yates, Mayer, and Kinsella (2011), it is not prudent for teachers to stagnate in their current roles without developing themselves through new learning opportunities. In the same vein, Frost (2012) mentions that having continuous professional development is productive for the teachers. Salleh and Dimmock (2012) are more specific on the purposes of TPD in their study. They argue that the policy of TPD concerns mostly on improving teachers' competency to meet academic objectives and students' development. This idea is also reinforced by Banks and Mayes (2012) who argue that TPD is "the acquisition or extension of the knowledge, understanding, skills and abilities that will enable individual teachers and the schools..." (p. 12). From this arguments, it is clear that teachers are advised to continuously enhance their knowledge and skills in teaching.

Teachers usually attend professional development programs to develop their pedagogical practice, reflect on their teaching experience, research, and practice, to "contribute to the professional life of the school" (Banks \& Mayes, 2012, p. 12). Besides, Banks and Mayes (2012) also state that professional development allows the individual teachers to uphold and develop the educational practices that have been done well, to be critically aware of the educational policy, and to develop the teachers' understanding of changes in the society, for example in terms of technology. 
The above idea is significant because the number of studies as such is still limited in Indonesian contexts. A few of the studies are, among others, a study by Sari (2012) that examines the issues of online learning community to improve teachers' professionalism. Next, Tanang and Abu (2014) examine the effects of effective TPD towards continuous PD based on some factors, such as pedagogic skills and various learning activities. Meanwhile, Zein (2015) focuses on how to overcome the deficiency of teacher's quality in Indonesia and also what teachers need in the professional development. Understanding the contexts and findings of those studies, the researchers propose a different angle as it focuses on the variety of TPD activities and programs provided by the government and also the challenges faced by the teachers. To this date, such focus of TPD study is still underrepresented.

There are several factors of TPD programs as discussed in previous studies which can be used to build on more comprehensive knowledge. Banks and Mayes (2012) believe that by having professional development program, teachers can reflect on their commitment to teaching. Reflecting on teachers' commitments in their profession is imperative as it can affect what they want to do later in their teaching career development. In accordance with the TPD program, Whitworth and Chiu (2015) in their study mention three factors that affect professional development, namely, teachers' motivation, school culture, and working conditions (p. 132). Teachers' motivations become the first factor because this aspect plays an important point. Next, school culture, which substantially stems from collegial atmosphere in school, may affect teachers' decisions in continuing their profession and developing themselves by attending professional development. The third factor relates to the teachers' working conditions and job satisfaction in school. It may be caused by the time they spent in the school, the salary they received, the students, and other aspects in the school (Whitworth \& Chiu, 2015). Slight different from the previous TPD research, a study by Misbahuddin (2013) demonstrated that the factors inhibiting the development of teacher profession in South Sulawesi are related to the lack of awareness of teachers in developing the profession continuously, the lack of confidence in the training, the lack of opportunity to develop skills, and the lack of attention from local government to the teacher network's activities.

From the background previously described, the following two research questions are proposed:

1. What have the English teachers in junior high schools in Cilacap done to develop their teacher professionalism?

2. What are the challenges for the teachers' professional development they experienced?

\section{METHOD}

This study was a qualitative study using a small survey and in-depth interview as the methods of data collection. The researchers focused on the respondents' points of view regarding their professional development program. All data collected in this study were elaborated in the form of narrative account in order to get a better understanding about the results. The data collected were also analysed inductively to make sure that the researchers captured the responses of the respondents accurately.

Due to the time available, the researchers used purposive sampling. According to Wahyuni (2012, p. 33), purposive sampling is one of the strategies to collect data by selecting the respondents based on specific criteria relevant to the research question. The purposive sampling here was used to choose the schools, not the respondents. Therefore, since there are 258 junior high schools in Cilacap Regency, the researchers limited the study to seven junior high schools from four sub-districts (out of 24 sub-districts) in Cilacap Regency, namely, Center Cilacap, South Cilacap, Jeruklegi, and Kawunganten. Those seven schools, consisting of three state junior high schools and four private junior high schools, were chosen because the researchers wanted to know the TPD in two different types of schools (state and private schools) in two different parts of the region: rural and urban areas. Meanwhile, the respondents were nineteen in-service junior high school English teachers. Sixteen female teachers $(84.2 \%)$ and 3 male teachers (15.8\%) participated in this study. The age range of the respondents was between 25 and 59 years old and the teaching experiences range from 3 to more than 20 years. Initially, the researchers contacted the respondents whether or not they consented to participate in this study voluntarily. The background information of the respondents could be seen in the following figure. 
Age

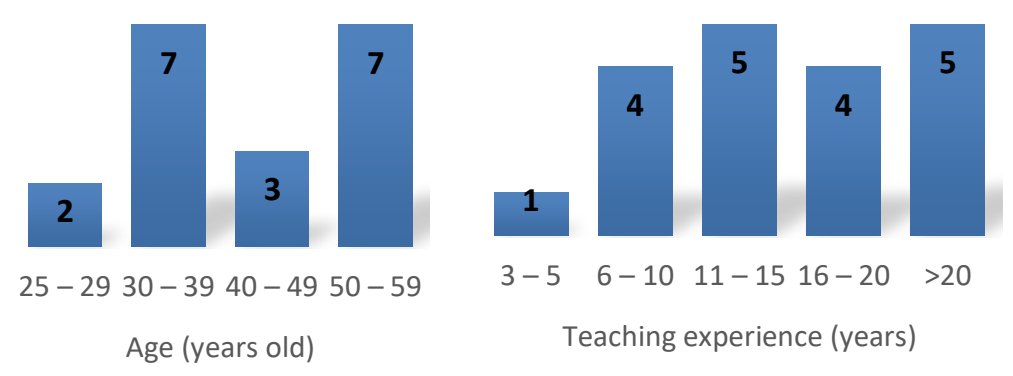

Figure 1. The background information of the respondents

For data collection, a questionnaire was used as one of the research instruments. The questionnaire was adapted from OECD Teaching and Learning International Survey (TALIS) by the Organization for Economic Cooperation and Development (OECD, 2016). OECD questionnaire model was used in this study as the questionnaire enquired information about school education and policy which suited Indonesian context. This was also to investigate the professional development activities carried out by the respondents. After getting and analysing the result of questionnaire, the researchers did indepth interviews with five English teachers to get a better understanding about their experiences in attending TPD program in Cilacap Regency. The interviews lasted for about 30-90 minutes. The discussion covered some areas about teaching and TPD program. In choosing the interviewees, the researchers also used purposive sampling based on the questionnaire responses which really met the criteria for answering this study.

In this study, the quantitative data from the questionnaire were analysed using descriptive statistics. The researchers focused on the total responses of each question in numbers and percentage. Then, the researchers analysed the qualitative data in a form of descriptive narrative to better understand the respondents' answers.

\section{RESULTS AND DISCUSSION}

From the results of the questionnaire and interview, the researchers classified those results into two parts which examine teachers' experiences in pursuing TPD programs and how they perceived the programs. The first part analyses the programs carried out by the teachers to develop their professionalism. The second was about the challenges they faced in following the programs. Each of them is elaborated as follows.

\section{TPD programs in Cilacap Regency}

Based on the interview done with one employee of Department of Education and Culture in Cilacap Regency, there were some programs provided to develop teacher professionalism. They were technical training, workshop, and continuous professional development through MGMP which covered professional development and teacher's competency. Those programs were done through full online learning and blended learning for continuous professional development. In doing those programs, the government provided financial supports from the Center of Government Budget through Pusat Pengembangan Pendidik dan Tenaga Kependidikan (The Centre of Education Staff Development) for every subject.

Teachers' Participations on Programs Provided

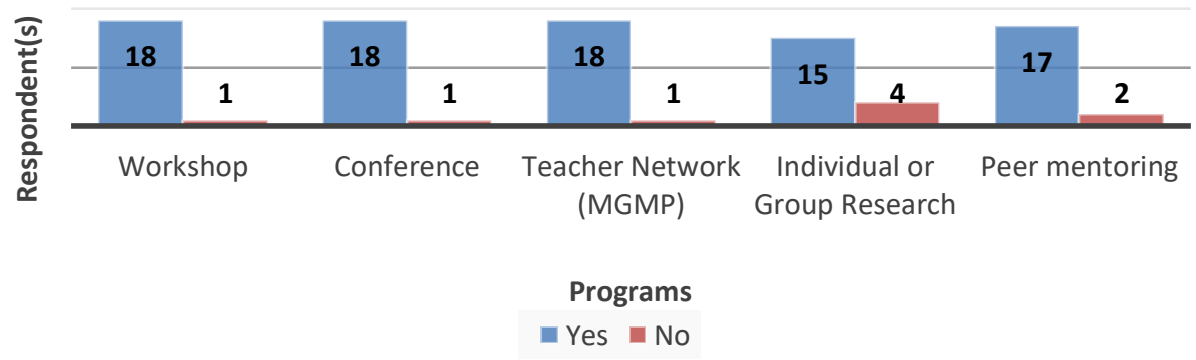

Figure 2. Teachers' participations in TPD 
The results of questionnaire revealed that most of the respondents experienced the programs or activities provided by both teacher network and government during their teaching. 91\% respondents have experienced TPD programs, namely, workshop, conference, teacher network, individual or group research, and peer mentoring. They remarked that TPD programs gave meaningful impacts for them. However, from the above figure, it could be seen that the respondents had less interest in doing individual or group research. Only 15 respondents clearly indicated that they conducted individual or group research. The following is the interview excerpt from Betty, explaining the reason and the consequence of doing an educational research:

"Doing a classroom action research consumes so much time. Therefore, this limits teachers to do the research. Teachers should have enough time to do it. (In addition), if there is no further action in doing the research, it will not do any good." (Betty, interview)

Here, Betty thought that doing a classroom action research should not be done halfway. Betty realized that the results would not be useful if she did not do the research well. However, when it was done well and thoroughly, the teachers did not have time to do it. Betty added that in doing the research, she did not have any other options to choose. Therefore, she had to conduct a research because the government asked her to do so. It was a kind of dilemma for teachers.

From those TPD programs in Figure 2, 11 respondents $(57.89 \%)$ said that they did not need to pay for the programs. However, 8 respondents $(42.11 \%)$ said that they should top up the fee to follow the programs. As what one of the teachers said, for teacher network (MGMP) programs, they needed to pay some amount to follow the program. However, the teacher did not literally pay it by themselves as it is often organized by their schools. Only sometimes did they use their own professional incentives to join the TPD activities. Most of the teachers in this study shared more or less the same TPD programs, such as technical training, curriculum 2013 and graduate competence analysis to prepare for the national examination.

\section{The challenges of TPD in Cilacap Regency}

In doing the programs to develop English teachers' professionalism in Cilacap, there were some challenges faced by the English teachers. Based on the questionnaire results, the challenges that were found to have prevented teachers to participate more in professional development in Cilacap were classified into seven challenges. They were conflicting schedule, limited time because of family responsibility, inadequate prerequisites for TPD, lack of employer support, expensive program, no suitable program offered, and lack of information. Meanwhile, Zein (2015) reported a study about professional development in Indonesia had some affecting factors, such as inadequate in-service education, inadequate teacher educators, issues with training management, and ambiguous selection of training participants. However, compared to this study, he did not mention that program timing became one of the challenges of TPD.

Moreover, those factors were in line with a study by Tanang and Abu (2014) which indicated that "Time management, cost, bureaucracy system, and the internal factors of teachers, such as personality, motivation, and commitment are still the main impediment challenges of teaching profession" (p. 31). Furthermore, as it can be seen that the biggest challenge faced by the respondents in following professional development programs in this study was about the conflicted schedule. Ten out of nineteen respondents $(52.63 \%)$ agreed that they were hindered by the time of the programs. 


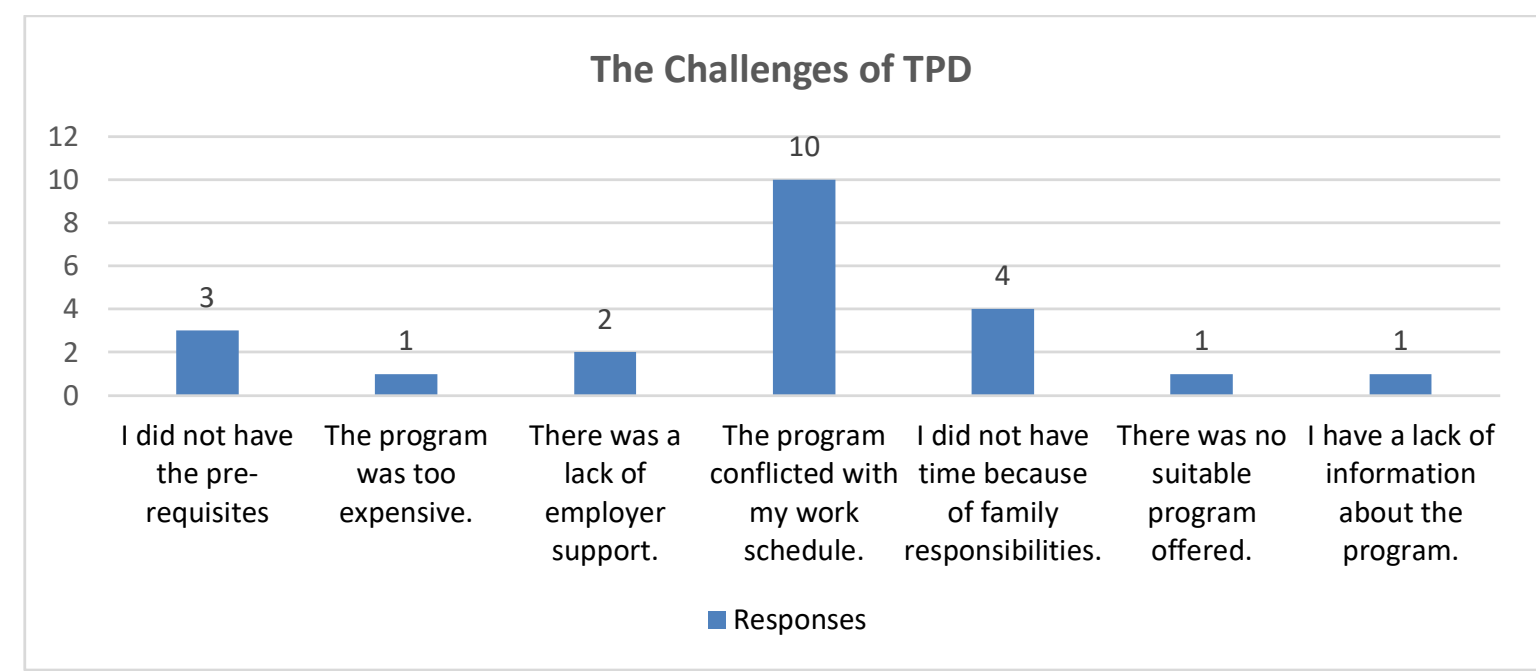

Figure 3. Challenges of TPD

From Figure 3, it is clearly seen that there are two crucial factors influencing the respondents to take part in the TPD programs. The first challenge concerns with program timing. The researchers saw that program timing was the most crucial thing because this could affect other factors, for example the family responsibility. Next, another challenge was about the lack of information received. Although there was only one respondent revealed that she had a lack of information, the researchers saw this as a serious problem to discuss because the information about TPD programs was the very first thing the teachers needed to develop themselves.

\section{Program timing}

In his research, Zein (2015) argues that the only matter regarding to time management for the teachers was the deliberately shortened duration by the administrator of the TPD program. The government usually reduced the time of TPD, for example from three-day program into just one day, which certainly disadvantaged them. Meanwhile, in this research, the crucial problem was the conflicted schedule as TPD programs were usually held during the school working hours. Thus, in order to follow the programs, those teachers had to leave their students. As a substitute for being absent, the teachers should give assignments for the students for one day or even more (up to 10 days), depending on how long the programs were planned. This became a big problem because after the teachers returned from the programs, they were faced by students' enormous tasks which should be checked and evaluated. The following is one of the respondents' comments on this experience:
"TPD program is usually held exactly at the same time of my teaching schedule. My students felt abandoned because I left them. Moreover, I cannot deliver the materials to my students effectively." (Steve)

From this point, it is obvious that the program schedule became the biggest barrier. However, this problem did not only happen to the respondents in Cilacap Regency, but also those teachers in South Sulawesi (Indonesia) as Tanang and Abu (2014) have mentioned earlier. This shows that this problem did not only occur in one particular area in Indonesia. In addition, it would seem that this program timing also affected the respondents' responsibilities in their families. It was because when the program was done in 10 days, the respondents should leave their families for that long.

Apart from the problem above, those teachers felt divided from their concern to improve their professionalism and to accompany their students' learning process, as well as their families as an integral part of their life responsibility. Meanhwile, the teachers understand how important it is to participate in TPD programs, they have already had enough understanding of the consequence, which often cannot be easily resolved. The teachers were faced with the tough discernment on their intrinsic motivation as a teacher against extrinsic motivation, for example to get incentives or a duty obligation. Indeed, Zein's (2015) study discloses that TPD implementation in Indonesia needs to be evaluated as teachers' participations in TPD programs were often not professionally oriented.

\section{Lack of information}

Cilacap Regency consists of 24 sub-districts with 275 junior high schools. Although The 
ENGLISH REVIEW: Journal of English Education Volume 8, Issue 1, December 2019

Department of Education and Culture of Cilacap already distributed information about TPD programs through letters for every school or Facebook and WhatsApp group, the information given by the government may not be received and informed well by the teachers in the rural areas of Cilacap Regency. In this study, two teachers from the rural areas (Jeruklegi and Kawunganten) revealed that they often did not get enough information about TPD programs held by the teacher network in Cilacap Regency. Moreover, this problem has a similarity with Zein's (2015) study which mentions that there were very limited and not widely accessible programs in rural areas (p. 8). A teacher shared an experience about one of her problems as follows.

"State schools perhaps often get the information about MGMP; but, in this school we rarely get the invitation to follow MGMP. I think they prioritize the state schools rather than the private schools. I do not know whether this also happens to another school or not. However, this school hardly received the invitation." (Diane)

Diane saw that there was a gap between state schools and private schools in terms of information about TPD programs. In short, the information given by the teacher network was not distributed well. Diane also described that if the teacher network meeting was done regularly, it would give some benefits since teachers could share about the teaching practices and materials that were used as a standard in the regency. Indeed, as what Soebari and Aldridge (2016) mentioned in their study, the teacher network is expected to help teachers to obtain various models of teaching and learning materials. Thus, they can prepare the students to be more creative, critical, and skilful. Having lack of information about the teacher network meeting was found as disadvantaging her in teaching. For example, she said that she did not know the limitation (scope) of materials used for the mid semester test or even for the final test. She was just guessing and trying to look at the last year questions of the test.

It could be inferred that the teachers needed TPD programs to support their teaching. However, in Cilacap Regency, some of the schools still required the printed invitation letter for the purpose of teacher network administration. When the distance of schools was
p-ISSN 2301-7554, e-ISSN 2541-3643

https://journal.uniku.ac.id/index.php/ERJEE

quite far from the central government, it would also be quite difficult to send teachers the printed letters. This situation connects well with the findings from Tanang and Abu (2014), arguing that "the level of participation and motivation of teachers to share and disseminate the experience is interrupted by communication" (p. 29). Tanang and Abu (2014) are right in saying that the teachers' motivation, whether intrinsic or extrinsic, were often compromised by the information distribution problems. Whereas, teacher motivation is indeed one key factor that affect professional development (Whitworth \& Chiu, 2015, p. 132).

Based on previous discussion, it is necessary to evaluate how the information of TPD programs is disseminated. It is because there are some teachers who do not have enough information of TPD programs so they cannot take a part on it. Whereas, Widodo and Riandi (2013) argue that the success or failure of TPD programs depends on the participations of the teachers. When the teachers do not participate in TPD programs because of the lack of information, it leads to the failure of TPD programs and delays teachers' professional development. As what Rahman (2016) also mentions, the schools with low levels of social and economic conditions (those which are in the rural areas) should get the same information and assistance in TPD practices as the schools which have high levels of social and economic conditions. Therefore, the government should pay attention to all the schools without exceptions. The government should also try to close the gap between teachers in rural and urban areas and also between state and private schools.

\section{Opportunities to improve TPD programs}

After understanding the challenges found in TPD programs, the researchers tried to assess the opportunities in terms of teachers' needs on the materials of TPD programs which were expected to be beneficial for them. Eight classifications of materials are identified as the English teachers' needs, namely, student assessment, classroom management, knowledge and understanding of English, content of performance standards, giving instruction, ICT skills for teaching, teaching students with special learning needs, and school management and administration (see Figure 4). 


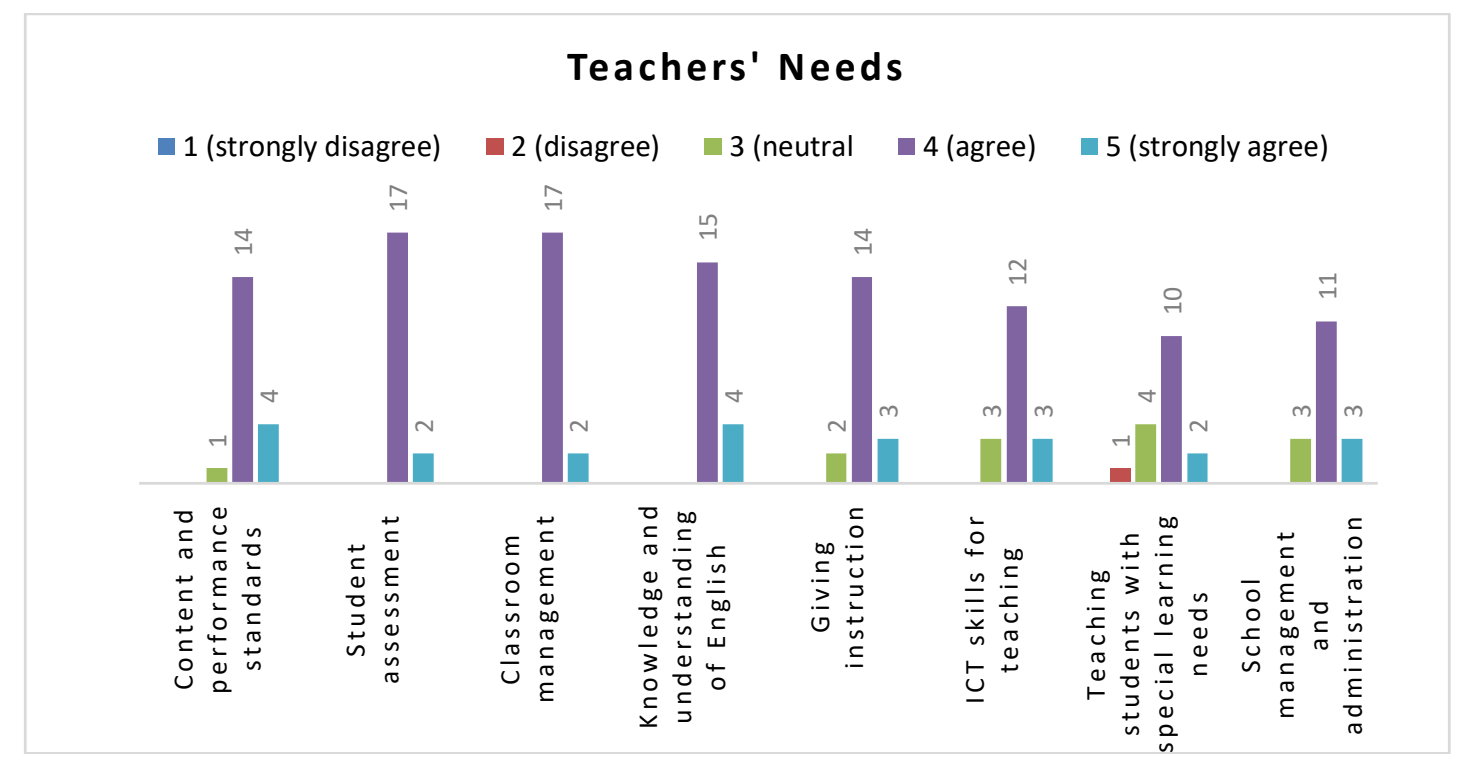

Figure 4. Needs assessment for TPD

From Figure 4, it could be seen that most of the teachers wanted to have more knowledge about students' assessment and classroom management. This is partially in line with Tanang and Abu's (2014) findings arguing that TPD programs are expected to focus on specific training for pedagogy, subject content knowledge, and classroom management which are appropriate to teachers' current needs (p. 36). It was because in following TPD programs, the respondents usually only received materials about how to make lesson plans and general knowledge about the 2013 curriculum. This problem also occurred in Zein's (2015) research which depicts the situation when the teachers mostly got learning theories and had limited chances to learn the practical input. Referring to the government TPD programs, which more often than not concerned with technicality and general knowledge, the respondents expected to have more practical training or workshop to develop their teacher professionalism. Therefore, rather than predominantly focusing only on the theories, the participants infer that they should focus more on the real teaching practices.

The other topic that did not catch the teachers' interest was about teaching students with special learning needs; and, school management and administration. For the latter, only 11 respondents thought that it was necessary to learn about school management and administration. The following interview result gave clearer insights why learning about student assessment was important.
"I was asked by a supervisor from the Education Office what remedial test was. I replied that for those who have already got scores above the average, the remedial test is used as enrichment. I usually divide the scores, but the supervisor said that it was wrong. Instead, the supervisor said that we should only use the student' highest score, without dividing the score." (Betty)

It could be inferred that before Betty was informed by the supervisor, she did not know how to assess students' remedial tests correctly. Thanks to TPD programs, Betty is provided with feedback on how to assess students' works and minimize such misunderstanding.

The other teachers' need for TPD relates with classroom management as it is expressed by Marie.

"As far as the classroom management is concerned, students' misbehaviour in class has now also taken different forms. In the past, the students did not have smartphones. Now, the students have smartphones, even for those living in the distant village. This really affects the teaching process in negative ways. Therefore, we as teachers should be trained how to use smartphones for learning in the classroom. Besides, we should be given a lesson how to handle the students to use smartphones properly. If there is such a workshop, we will know how to handle students" (Marie).

From this point, it is necessary for teachers to learn how to manage the classroom because that kind of problem does not only happen to one teacher. Students may see gadgets or smartphones as tools which are exceptionally exciting. However, it can disturb the teaching and learning process if the students do not know how 
ENGLISH REVIEW: Journal of English Education Volume 8, Issue 1, December 2019

to use the gadgets properly. Besides, given the fact that the teachers also do not have enough opportunities to get the knowledge of how to cope with technology in the classroom, the teachers will always find the difficulties in managing the students. Lazar (2015) clearly reveals that a teacher should be able to provide interesting and effective classroom activities using technology to motivate students in learning. Tanang and Abu (2014) are more comprehensive in seeing this classroom learning problem. Workshop may be important, but more importantly is the teachers taking a good time to reflect about their educational practices. Besides, they need "initial preparation in their methodologies, language fluency for teaching instruction, instructional materials, and strategy for classroom management before entering the class" (Tanang \& Abu, 2014, p. 36). Therefore, having peer mentoring or supervision from the principal was important so that the teachers do not only learn about the technicality, but also practicing and experiencing by themselves. Thus, the teachers could learn more to develop themselves from the feedback given.

From the above exploration regarding teachers' needs for TPD, it is essential to understand the teachers' needs first (bottom up) rather than simply providing trainings (topdown). This may not be simple as teachers' needs may be different from one another, from one regions to different regions. In the same vein, Zein (2015) explains that TPD programs designed by bureaucrats "often did not match the needs of the teachers as well as the contextual situations in which their work demonstrates the administrators' narrow understanding of the depth of English language teaching" (p. 12). It is in line with the study by Utami (2015) arguing that the government should do a little research regarding the teachers' need so that the teachers can get expected materials from the programs offered. Therefore, the government should be more aware of this situation and be able to provide programs suitable to teachers and students' needs especially about classroom management and also how to integrate ICT to the classroom discussion.

\section{CONCLUSION}

This paper has demonstrated challenges and opportunities of TPD programs of the English teachers of junior high school in one of Indonesia's regencies. Nonetheless, there are still some challenges facing the program
p-ISSN 2301-7554, e-ISSN 2541-3643 https://journal.uniku.ac.id/index.php/ERJEE

implementation. The challenges are about the program timing, lack of information, and limitation of the programs. Most teachers encountered a lot of challenges when the programs are organized during the working days due to family problems as well as additional workload problems for checking students' assignments. Therefore, it is critical for the government to understand what the teachers need and feel in following TPD programs. These measures can engender more meaningful TPD programs for the teachers in general.

In terms of the research scope, this study investigated limited number of participants in one small region. Therefore, other researchers can use this study as a reference to do further studies by including larger respondents and schools to accommodate richer data in different parts of Indonesia. As an integral part of this study, the bottom-up approach by looking into the teachers' needs to participate in TPD is also a key factor which requires further investigation in a larger scale.

\section{REFERENCES}

Banks, F., \& Mayes, A. S. (2012). Early professional development for teachers. London: David Fulton Publishers.

Darling-Hammond, L., Hyler, M. E., \& Gardner, M. (2017). Effective teacher professional development. Palo Alto, CA: Learning Policy Institute.

Fahmi, M., Maulana, A., \& Yusuf, A. A. (2011). Teacher certification in Indonesia: A confusion between means and ends. Bandung: Padjajaran University.

Frost, D. (2012). From professional development to system change: Teacher leadership and innovation. Professional Development in Education, 38(2), 205-227. doi: 10.1080/19415257.2012.657861.

Kennedy, M. M. (2016). How does professional development improve teaching? Review of Educational Research, $X X, 1-36$. doi: 10.3102/0034654315626800.

Kuswandono, P. (2014). Proceeding of teaching and learning of English in Asia (TLEIA): Challenges of teacher certification in Indonesia. Sintok: Universiti Utara Malaysia.

Lazar, S. (2015). The importance of educational technology in teaching. International Journal of Cognitive Research in Science, Engineering and Education, 3(1), 111-114.

Misbahuddin. (2013). The development of teacher profession (Unpublished Thesis). Program Pascasarjana Universitas Negeri Makassar. 
OECD. (2016). TALIS supporting teacher professionalism: Insights from TALIS 2013. Paris: OECD Publishing.

Rahman, A. (2016). Teacher professional development in Indonesia: The influences of learning activities, teacher characteristics and school conditions (Doctoral thesis). Retrieved from https://ro.uow.edu.au/theses/4721.

Salleh, H., \& Dimmock, C. (2012). Singapore schools and professional learning communities: Teacher professional development and school leadership in an Asian hierarchical system. Educational Review, 64(4), 405-424. doi: 10.1080/00131911.2011.62511.

Sari, E. R. (2012). Online learning community: A case study of teacher professional development in Indonesia. Intercultural Education, 23(1), 63-72.

Soebari, T., \& Aldridge, J. M. (2016). Investigating the differential effectiveness of a teacher professional development programme for rural and urban classrooms in Indonesia. Teacher Development, 20(5), 701-722. doi: 10.1080/13664530.2016.1185031.

Tanang, H., \& Abu, B. (2014). Teacher professionalism and professional development practices in South Sulawesi, Indonesia. Journal of Curriculum and Teaching, 3(2), 25-42. doi: 10.5430/jct.v3n2p25.

Taylor, M., Yates, A., Meyer, L. H., \& Kinsella, P. (2011). Teacher professional leadership in support of teacher professional development. Teaching and Teacher Education, 27(1), 85-94. doi: 10.1016/j.tate.2010.07.005.

Utami, I. G. A. L. P. (2015). Teacher certification program in Indonesia: Problems and recommendation for the betterment of the program. International Journal of English and Education, 4(2), 471-481.

Wahyudi, K. E., Supranoto, \& Suji. (2012). Measuring performance of teacher certification program. International Journal of Administrative Science \& Organization, 19(3).

Wahyuni, S. (2012). Qualitative research method: Theory and practice. Jakarta: Salemba Empat.

Whitworth, B. A., \& Chiu, J. L. (2015). Professional development and teacher change: The missing leadership link. Journal of Science Teacher Education, 26(2), 121-137. doi: 10.1007/s10972014-9411-2.

Widodo, A., \& Riandi. (2013). Dual-mode teacher professional development: Challenges and revisioning future TPD in Indonesia. Teacher Development: An International Journal of Teachers' Professional Development, 17(3), 380392. doi: 10.1080/13664530.2013.813757.

Zein, S. (2015). Factors affecting the professional development of elementary English teachers. Professional Development in Education, 1-18. doi: 10.1080/19415257.2015.1005243. 